\title{
Life-threatening bleeding following Barrett's surveillance biopsies
}

A fit 88-year-old man attended for Barrett's esophagus (BE) surveillance endoscopy. He was initially referred to our centre in 2008 with a diagnosis of high grade dysplasia (HGD) based on random biopsies at a district general hospital. He underwent an uneventful endoscopic mucosal resection for a visible flat lesion (Paris 0-IIa) located $30 \mathrm{~cm}$ from the incisors. The need and appropriateness of continuing surveillance [1] was discussed with him, considering his age and comorbidity (hypertension, for which he was taking calcium channel blockers and aspirin [75 mg]). He had a good functional status (American Society of Anesthesiologists [ASA] grade 2) and he wished to continue surveillance. Trimodal endoscopy (high-resolution endoscopy, autofluorescence imaging, and narrow band imaging) revealed a flat area suspicious for dysplasia above the gastroesophageal junction at $35 \mathrm{~cm}$ ( Figs. $1-3)$.

This area was target biopsied (three biopsies) and standard four quadrant biopsy samples were taken every $2 \mathrm{~cm}$. There was no significant bleeding at the end of procedure.

The patient developed melena 24 hours after the endoscopy and collapsed at home. At the emergency department, he was hypotensive and tachycardic (blood pressure $90 / 60 \mathrm{mmHg}$, pulse rate 112 beats/min). His hemoglobin was $7.6 \mathrm{~g} / \mathrm{dL}$ (a drop of $5 \mathrm{~g} / \mathrm{dL}$ ) and the urea concentration was raised $(26.7 \mathrm{mmol} / \mathrm{L})$. Platelet count and coagulation screen were normal. He was resuscitated and an endoscopy revealed an adherent clot and pigmented base at the target biopsy site ( $\bullet$ Fig. 4).

No endoscopic intervention was carried out as the bleeding stopped spontaneously. The patient was given an intravenous infusion of omeprazole and he made an uneventful recovery. The targeted biopsies were later confirmed to have HGD on histological examination ( $\bullet$ Fig. 5).

The patient was offered endoscopic therapy for the HGD after discontinuing aspirin, but he declined further endoscopy. He is asymptomatic at 9 months of clinical follow-up.

Significant bleeding from mucosal biopsy sites is thought to be a rare event in the absence of coagulopathy, thrombocytope-

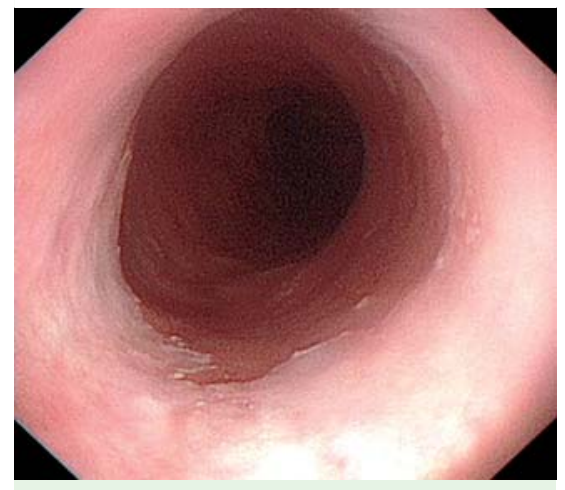

Fig. 1 High resolution white light endoscopy showing long segment Barrett's esophagus.

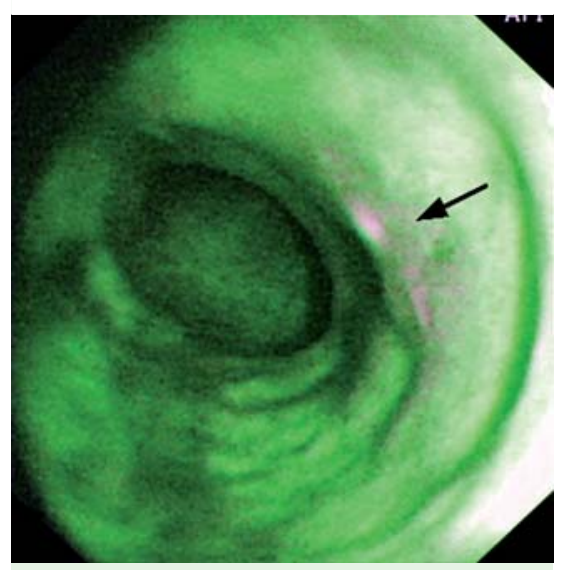

Fig. 2 Autofluorescence imaging showing an abnormal low-intensity area (arrow) above the gastroesophageal junction.

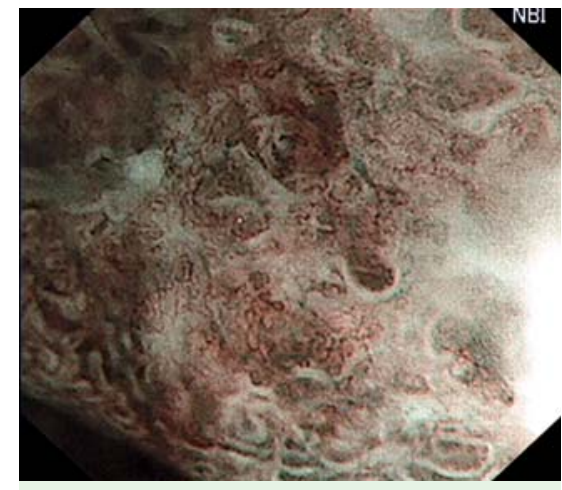

Fig. 3 Narrow band imaging with magnification showing irregular vasculature and distorted pit patterns suggestive of dysplasia.

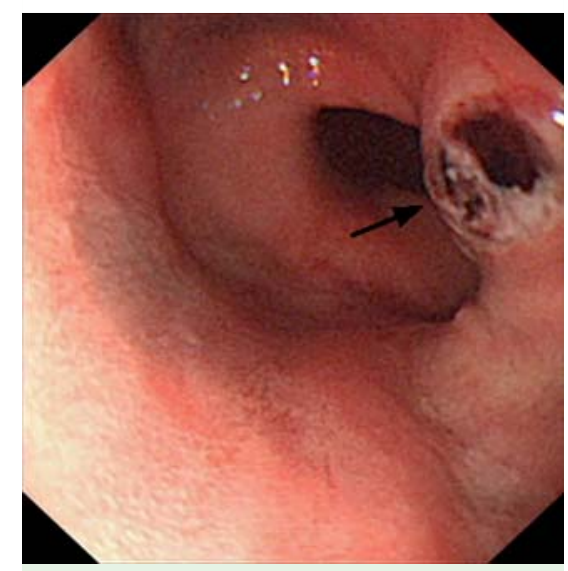

Fig. 4 The target biopsy site above the gastroesophageal junction with stigmata of recent bleed (arrow).

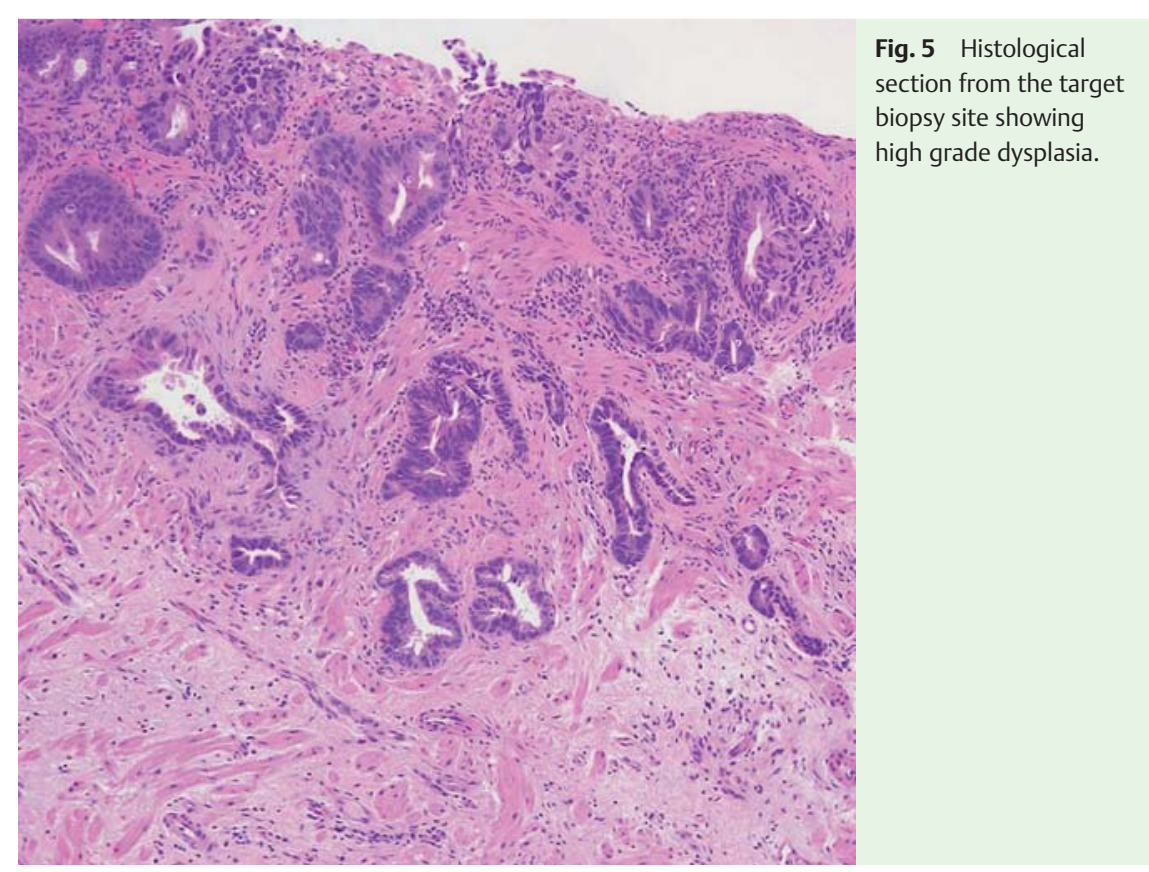


nia, and portal hypertension [2]. Bleeding following gastric biopsies has been reported $[3,4]$, however, there are no similar reports in relation to BE surveillance. Early cancer and intraepithelial neoplasia in BE are associated with increased vascularity related to neoangiogenesis [5]. Aspirin is not known to increase the risk of bleeding after biopsies [6]. However, a cumulative risk associated with aspirin use and dysplasia-related angiogenesis might have contributed to the bleeding in our patient, and this needs to be considered as a potential risk factor in BE surveillance.

Competing interests: Dr. Ragunath has received educational grants, speaker honoraria and research support from Olympus-Keymed, UK.

Endoscopy_UCTN_Code_CPL_1AH_2AB

\section{J. Mannath ${ }^{1}$, V. Subramanian ${ }^{1}$,} P. V. Kaye ${ }^{2}$, K. Ragunath ${ }^{1}$

1 Nottingham Digestive Diseases Centre, NIHR Biomedical Research Unit, Nottingham University Hospitals NHS Trust, Nottingham, UK

2 Department of Histopathology, Nottingham University Hospitals NHS Trust, Nottingham, UK

\section{References}

1 Hirota WK, Zuckerman MJ, Adler DG et al. ASGE guideline: the role of endoscopy in the surveillance of premalignant conditions of the upper GI tract. Gastrointest Endosc 2006; 63: $570-580$

2 Silvis SE, Nebel O, Rogers $G$ et al. Endoscopic complications. Results of the 1974 American Society for Gastrointestinal Endoscopy Survey. JAMA 1976; 235: 928 - 930

3 Armelao F, Tasini E. An unfortunate (and inappropriate) gastric biopsy. Endoscopy 2008; 40 (Suppl 2): E27

$4 \mathrm{Vu}$ CK, Korman MG, Bejer I et al. Gastrointestinal bleeding after cold biopsy. Am J Gastroenterol 1998; 93: 1141 - 1143
5 Couvelard A, Paraf F, Gratio Vet al. Angiogenesis in the neoplastic sequence of Barrett's oesophagus. Correlation with VEGF expression. J Pathol 2000; 192: 14-18

6 O'Laughlin JC, Hoftiezer JW, Mahoney JP et al. Does aspirin prolong bleeding from gastric biopsies in man? Gastrointest Endosc 1981; 27: $1-5$

Bibliography

DOI $10.1055 / \mathrm{s}-0030-1255717$

Endoscopy 2010; 42: E211 -E212

(c) Georg Thieme Verlag KG Stuttgart · New York . ISSN 0013-726X

\section{Corresponding author}

\section{K. Ragunath, MD, M Phil, FRCP}

Associate Professor and Reader in Endoscopy Nottingham Digestive Diseases Centre NIHR Biomedical Research Unit Nottingham University Hospitals NHS Trust Nottingham NG7 2UH

UK

Fax: +44-115-82-31090

K.Ragunath@nottingham.ac.uk 